\title{
Errata
}

\section{Erratum: A General Waveguide Circuit Theory}

\section{Dylan F. Williams and Roger B. Marks}

National Institute of Standards and Technology, Boulder, CO 80305

dylan@boulder.nist.gov

J. Res. Natl. Inst. Stand. Technol., Volume 97, Number 5, September-October 1992, p. 533 http://dx.doi.org/10.6028/jres.097.024

Erratum: Equations D5 and E3 in the appendices of [1] contain typographical errors. They should read

$$
\mathrm{W} \equiv \operatorname{diag}\left(\mathrm{W}_{n}\right) ; \mathrm{W}_{n} \equiv \frac{\tilde{p}_{0 n}}{v_{0 n} i_{0 n}}=\frac{v_{0 n}^{*}}{v_{0 n}} \frac{\tilde{p}_{0 n}}{p_{0 n}^{*}}
$$

and

$$
\mathrm{U} \equiv \operatorname{diag}\left(\frac{\left|v_{0 m}\right|}{v_{0 m}} \frac{\sqrt{\operatorname{Re}\left(Z_{\mathrm{ref}}^{m}\right)}}{\left|Z_{\mathrm{ref}}^{m}\right|}\right) .
$$

Also, the reference to Eq. (20) just after equation (D5) should be a reference to Eq. (17). 